\title{
Neighbourhood size and the importance of barriers to gene flow in an intertidal snail
}

\author{
MICHAEL S. JOHNSON* \& ROBERT BLACK \\ Department of Zoology, University of Western Australia, Nedlands, Western Australia 6009, Australia
}

\begin{abstract}
The littorine gastropod Bembicium vittatum has direct development from benthic egg masses, and shows high levels of genetic subdivision in the Houtman Abrolhos Islands, Western Australia. Parallel studies of dispersal and the scale of variation of allozyme frequencies were used to estimate the extent of the neighbourhood, the area of complete genetic mixing. Estimates based on the variance of dispersal distances were 58 to $69 \mathrm{~m}$, very similar to the estimate of $62 \mathrm{~m}$ from the median dispersal distance. The allozymes indicated mixing over greater distances, up to 150 to 300 $\mathrm{m}$. Combined with estimates of population density at two sites, these values suggest neighbourhood sizes of 990 to 37200 adults. However, estimation of effective population size based on a model of isolation by distance gave very low values of 22 to 38 , raising doubts about the applicability of this method. Nevertheless, there was an overall pattern of isolation by distance along about $11 \mathrm{~km}$ of nearly continuous suitable habitat, with smooth clinal variation in allelic frequencies over distances of 2 to $6 \mathrm{~km}$ at individual loci. In contrast, there was no pattern of isolation by distance, and allelic frequencies showed less smooth patterns, along a discontinuous series of islands over the same distance. Within this discontinuous series, genetic subdivision, as measured by $G_{\mathrm{ST}}$, was twice as large at distances of $1 \mathrm{~km}$ as for populations on continuous shores, demonstrating the importance of even relatively short water gaps as barriers to gene flow in this directly developing intertidal species.
\end{abstract}

Keywords: Bembicium vittatum, gene flow, genetic subdivision, isolation by distance, littorine snail, neighbourhood.

\section{Introduction}

The scale of dispersal is fundamental to genetic and ecological processes affecting populations. It determines both the area in which self-recruitment of a population occurs and the spatial scale over which genetic divergence can occur (Slatkin, 1985). For continuous populations, the concept of the neighbourhood (Wright, 1969) provides the fundamental framework for examining genetic divergence. The size of the neighbourhood (where size refers to the breeding population) determines the potential for random drift to affect allelic frequencies. Genetic mixing over the area of the neighbourhood occurs each generation, so genetic differences within the neighbourhood cannot accumulate across generations. The neighbourhood is thus a basic unit of evolutionary divergence.

Several approaches have been used to determine the extent and size of the neighbourhood, and Slatkin (1985) categorized these as 'direct' methods and 'indirect' methods. Most direct approaches are based on mark-recapture studies to determine the extent of

${ }^{*}$ Correspondence. dispersal. Although obviously relevant, this approach has major practical difficulties. It is often difficult to measure dispersal across a full generation, including all life stages. This is particularly true in many marine species, for example, in which passive transport of unmarkable larvae may differ substantially from dispersal of adults. Occasional long-distance dispersal of marked individuals is easily missed, but such individuals have a disproportionate effect on the extent of the neighbourhood. It is also difficult to measure dispersal rates over enough generations to determine the importance of sporadic events.

Indirect estimates of the extent of the neighbourhood are based on patterns of variation of allelic frequencies. The rationale for using genetics to determine the extent of the neighbourhood is that genetic differentiation can accumulate only beyond the neighbourhood area, so that the point at which divergence begins to increase with increasing distance can be taken as the extent of the neighbourhood (e.g. Selander \& Kaufman, 1975; Richardson et al., 1986; Brown, 1991). More recently, a method of estimating neighbourhood size from a pattern of isolation by distance has been suggested (Slatkin \& Maddison, 1990; Slatkin, 1993). 
Although having the disadvantage of requiring inference of the underlying population structure from the genetic patterns that result from that structure, the genetic approaches have two advantages: first, they are quicker and easier than the direct approaches; second, they integrate effects of dispersal over periods of several generations, without depending on estimation of generation time.

Data on allozymes and DNA are increasingly being used to make quantitative estimates of population structure, but there are few comparisons of the direct and indirect estimation of neighbourhood size in the same study. On a large scale, both recoveries of tagged individuals and variation in allelic frequencies in skipjack tuna give estimates of the scale of mixing as about $1100 \mathrm{~km}$ across the Pacific (Richardson, 1983). At a much finer scale, mark-recapture studies in the helicid snail Cepaea nemoralis indicate that neighbourhoods are commonly around 30 to $40 \mathrm{~m}$ in diameter (Jones $e t$ al., 1977). Genetic comparisons in different populations give a similar result for both $C$. nemoralis (see Wallace, 1968 , p. 365) and another helicid, Helix aspersa (Selander \& Kaufman, 1975). Correspondence of direct and indirect estimates was found on a similarly fine scale for the clausiliid snail Albinaria corrugata (Schilthuizen \& Lombaerts, 1994) and the tropical palm Astrocaryum mexicana (Eguiarte et al., 1993). Although these results are encouraging, it is important to compare methods in a wide range of circumstances, to determine how robust they are.

In this paper, we use mark-recapture and genetic studies to examine the neighbourhood and scale of genetic subdivision in the intertidal snail Bembicium vittatum (Gastropoda: Littorinidae). This species lives in the high intertidal zone and lacks a planktonic larval stage, as the snails hatch directly from egg masses on the shore (Black et al., 1994). At the northern limit of its distribution, $B$. vittatum is abundant and widespread in the Houtman Abrolhos Islands $\left(29^{\circ} \mathrm{S}, 119^{\circ} \mathrm{E}\right)$, an archipelago of more than 100 small islands $70 \mathrm{~km}$ off the Western Australian coast. A study of allozymes in these populations found high levels of genetic subdivision, as expected for a species without planktonic dispersal (Johnson \& Black, 1991). However, the extent of genetic subdivision varied with habitat, raising the question of whether gene flow between islands could be high, possibly through transport of the small $(0.5 \mathrm{~mm})$ newly hatched snails. To provide the context in which to examine these patterns of genetic subdivision, we have used both direct and indirect methods to estimate the size and length of the neighbourhood, and we have made comparisons of the scales and patterns of allozyme variation in different areas, to test the effect of water gaps as barriers to dispersal. The com- parison of several methods highlights the difficulties of estimating the neighbourhood size.

\section{Materials and methods}

\section{Mark-recapture}

The mark-recapture study was conducted on Pelsaert Island, in the southernmost group of the Abrolhos Islands (Fig. 1). We chose this island because $B$. vittatum is common along most of its length of $11 \mathrm{~km}$, and there are no major barriers to the movement of snails along the shore. The site of the mark-recapture experiment was $100 \mathrm{~m}$ south of site 85 (Fig. 1), which we refer to as Noddy Shore. This area has relatively high densities of snails on a substrate of small coral fragments for more than a kilometre in either direction of the release site. Snails were marked with enamel spray paint (Taubman's Fiddly Bits) on the apical surface, and released in the centre of a $3 \mathrm{~m}$-wide grid that is used for regular censusing. The painting includes the margin of the aperture, thereby allowing measurement of the size-at-marking of the snails subsequently recaptured, so we could compare dispersal among snails of different sizes. The major mark-recapture experiment was begun in April 1993. At that time, the 434 unmarked snails on the grid were painted and replaced to their original metre. Most of these snails were greater than $6 \mathrm{~mm}$ in diameter. In addition 1046 small snails $(2-6 \mathrm{~mm})$ were collected from adjoining areas within $10 \mathrm{~m}$ of the release point, and marked with a different colour. These were used to ensure adequate numbers of recaptures of small snails. Resident snails had also been marked in December 1992, September 1992, and June 1992. A careful search of the study site was made in September 1993, 5 to 15 months following the release of marked snails. We carefully searched the shore in each $1 \mathrm{~m}$ interval between $80 \mathrm{~m}$ north and $80 \mathrm{~m}$ south of the release point. This length was chosen to give as thorough a sampling of the distribution of dispersal distances as was practicable.

Along these shores, $B$. vittatum occupies a zone approximaterly $3 \mathrm{~m}$ wide, so the distribution of the population is essentially linear north and south along the shore. This species does not occur on the eastern side of Pelsaert Island, and the nearest island to the west is $4 \mathrm{~km}$ away, so violation of the assumption of a linear distribution is highly unlikely. The length of the neighbourhood depends on both the standard deviation of the dispersal distances over a full generation and the shape of the distribution of those distances. The latter is much more important for a linear population than for one in two dimensions (Wright, 1969). For 
Fig. 1 Maps of Pelsaert Island and the linear series of islands in the Easter Group of the Houtman Abrolhos Islands, showing sampling sites of Bembicium vittatum on the large-scale transects. The inset shows the relative positions of the islands within the Pelsaert and Easter Groups.

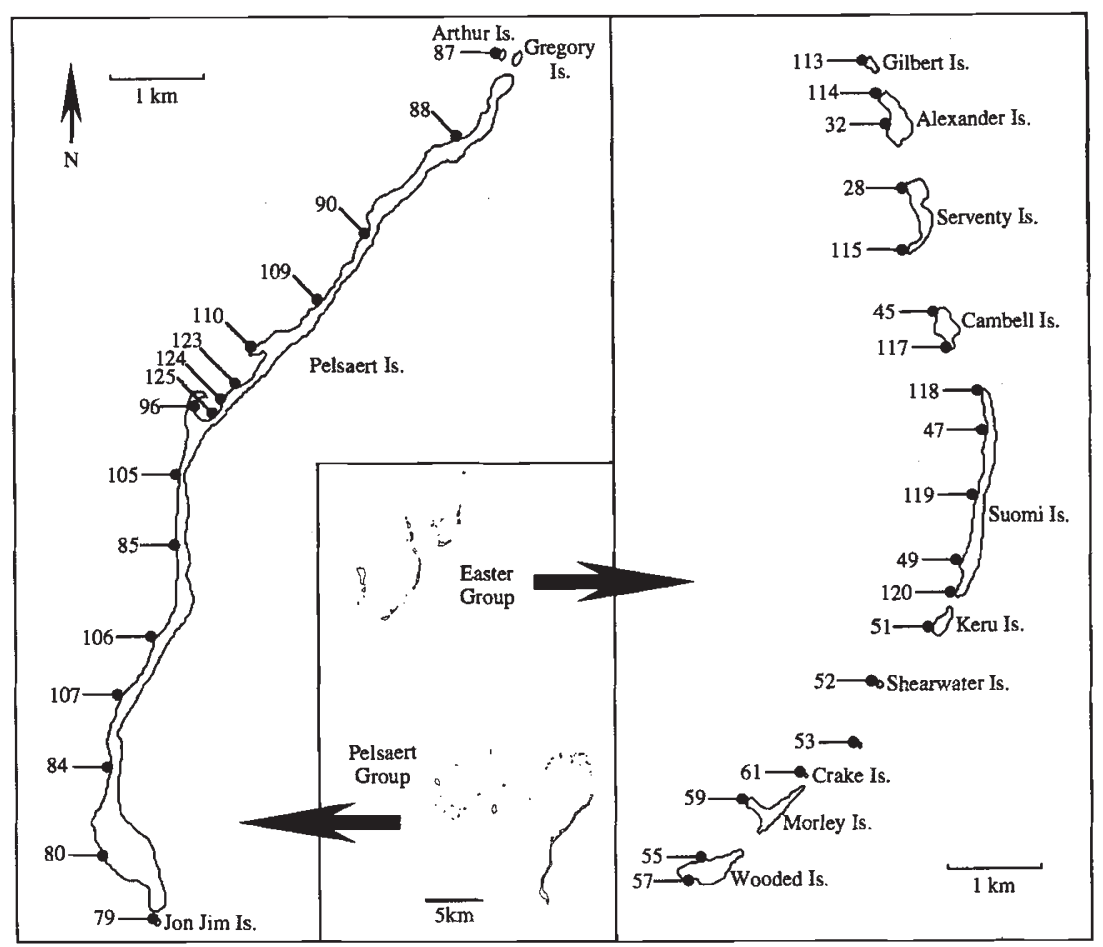

example, the length of the neighbourhood is $3.46 \sigma$ for a platykurtic distribution with the coefficient of kurtosis $\gamma_{2}=-1.20$, while it is only $1.46 \sigma$ for a leptokurtic distribution with $\gamma_{2}=22.20$. For a normal distribution $\left(\gamma_{2}=0\right)$, the relationship is $3.54 \sigma$. As emphasized by Wright, the shape of the distribution of dispersal distances changes over time, typically beginning as leptokurtic, but eventually becoming platykurtic. It is therefore crucial to determine both $\sigma$ and $\gamma_{2}$ over the period of a full generation. The estimated values of $\sigma$ and $\gamma_{2}$ are referred to as $s$ and $g_{2}$.

As part of a comparative demographic study at several sites (Black \& Johnson, unpublished), we have estimates of the average ages of adults from two shore sites on Pelsaert Island, Noddy Shore south of site 85 and Guano Jetty, site 84 (Fig. 1). Averaging the values from these sites, we have estimated that the time to reach adult size ( $8.5 \mathrm{~mm}$ diameter at Noddy Shore) is about 9 months. Mean annual survivorship of adults is about 0.028 . Based on these values, the mean age of the adults is 12 months. Although the estimate would be improved if we had age-specific survivorship and fecundity, we take 12 months as a reasonable estimate of the generation time. In a diffusion process, the variance of dispersal distances increases linearly with time. We estimated the neighbourhood length as $k \sqrt{ } s^{2}$, where $k$ depended on the kurtosis (Wright, 1969, p. 304) and $s^{2}$ is the variance in dispersal distances, linearly scaled to 12 months.
Another method of estimating the length of the neighbourhood is to use the median dispersal distance, rather than the standard deviation. For linear populations, "the length of the neighbourhood can be taken as about 2.8 times the range that includes half the parents without much error, irrespective of the kurtosis' (Wright, 1969, p. 306). We also attempted to estimate the neighbourhood using this approach.

The other parameter required to determine the size of the neighbourhood is the density of reproductive adults. We counted the snails at both the Noddy Shore and Guano Jetty sites seven times between February 1992 and September 1993. At each site, we calculated the average density of adults as the harmonic mean of densities at the different times, as is appropriate when considering the genetically effective population size (Wright, 1969). Noddy Shore has relatively high densities, but is typical of populations between sites 105 and 106 (Fig. 1). The lower numbers at Guano Jetty are more typical of much of the rest of the island.

\section{Electrophoretic comparisons}

Samples of adult $B$. vittatum were collected from three transects representing different spatial scales along Pelsaert Island. Twenty-eight samples of 48 adult snails each were collected from a $300 \mathrm{~m}$ transect along the shore south of site 85 . Each sample was collected within a $1 \mathrm{~m}$ interval, and the samples were distributed 
along the transect at metres $0,5,15,30,50,55,70,85$, $95,100,105,115,130,145,160,180,195,200,210$, $220,235,255,265,275,280,290,295$, and 300 from north to south. This distribution provided a minimum of five replicate comparisons at each $5 \mathrm{~m}$ interval for distances up to $200 \mathrm{~m}$. The release site for the markrecapture study was at the $102 \mathrm{~m}$ position on this transect, so the direct and indirect estimates of neighbourhood length were from the same area. The second transect was $1600 \mathrm{~m}$ long, and included the $300 \mathrm{~m}$ transect. Samples were taken at metres 0, 50, 100, 200, $300,400,500,550,650,700,800,850,950,1000$, $1100,1150,1250$, and 1300 north of the $300 \mathrm{~m}$ transect, and analysed with the samples from 50, 100, 200 and $300 \mathrm{~m}$ from that transect. The northern end of this $1600 \mathrm{~m}$ transect was north of site 105 . An additional set of five samples was collected between sites 110 and 96 , a distance of about $1 \mathrm{~km}$, and comparisons among these were included with those from the $1600 \mathrm{~m}$ transect. This set of 27 samples provided a minimum of five replicate comparisons for each $50 \mathrm{~m}$ interval up to $1 \mathrm{~km}$. Finally, the third transect was the entire length of Pelsaert Island, including 13 samples taken at intervals of 0.6 to $1.5 \mathrm{~km}$ (Fig. 1), in order to determine the large-scale patterns of allelic frequencies.

Pelsaert Island is continuous for nearly $11 \mathrm{~km}$. Jon Jim Island (site 79), at its southern end, is connected by an intertidal flat about $50 \mathrm{~m}$ across, and Arthur Island (site 87 ) is separated by a gap of less than $200 \mathrm{~m}$. B. vittatum is abundant along most of the sheltered western shore of Pelsaert Island, providing the longest series of connected populations in the Houtman Abrolhos, and the optimal area in which to examine the effects of dispersal with minimal barriers. To test for the effects of water gaps as barriers to gene flow, we took another set of samples along a linear series of islands in the Easter Group of the Abrolhos Islands, about $20 \mathrm{~km}$ northwest of Pelsaert Island (Fig. 1). The Easter series extended from the northern end of Gilbert Island to the southern end of Wooded Island, a distance almost identical to the length of Pelsaert Island. The sheltered lagoonal shores along their western margins are very similar to those on Pelsaert Island, and $B$. vittatum is abundant along most of their length. The major difference between the two is that the string in the Easter Group is broken by several water gaps of 200 to $800 \mathrm{~m}$. Thus, comparisons of levels of genetic subdivision at similar distances in the two groups provide a test of the possible significance of water gaps. For these comparisons, Keru Island and Suomi Island were classified as connected, as were Crake Island and Morley Island, because the separations are narrow intertidal platforms and not true water gaps.
Samples were frozen in liquid nitrogen in the field and transferred to $-70^{\circ} \mathrm{C}$ for up to 12 months prior to electrophoresis. Starch-gel electrophoresis was used to assay variation of 10 enzymes representing 13 polymorphic loci: arginine phosphokinase (EC 2.7.3.3; $A p k 1$ and $A p k 3$ loci); esterase (EC 3.1.1.-; Est4 locus); leucine aminopeptidase (EC 3.4.-.-; Lap1 locus); glutamate oxaloacetate transaminase (EC 2.6.1.1; Got1 locus); leucylglycylglycine peptidase (EC 3.4.1.3; Lggp locus); leucylproline peptidase (EC 3.4.1.3; Lpp locus); valylleucine peptidase (EC 3.4.1.3; Vlp1 and Vlp2 loci); mannose-6-phosphate isomerase (EC 5.3.1.8; Mpi locus); phosphogluconate dehydrogenase (EC 1.1.1.43; Pgd locus); phosphoglucomutase (EC 2.7.5.1; Pgm1 and Pgm2 loci). At each locus, alleles were labelled as a percentage of the mobility of their corresponding allozymes to that of the most common allele.

Because of the large size of the data set, it is not presented here, although the spatial patterns are shown graphically. A copy of the entire set of data is available from the authors.

\section{Analysis of genetic data}

The estimation of the extent of the neighbourhood from the genetic data is based on the notion that only beyond the neighbourhood can genetic divergence between subpopulations accumulate over generations. Thus, genetic differences should not be a function of distance within the neighbourhood, but should rise as a function of distance beyond the neighbourhood. We used Nei's (1973) $G_{\mathrm{ST}}$ as a pairwise measure of genetic subdivision between populations. Although $G_{\mathrm{ST}}$ (equivalent to $F_{\mathrm{ST}}$ ) is more widely used for sets of populations, it is appropriate as a pairwise measure when the interest is factors affecting genetic subdivision (Slatkin, 1993). Mean values of $G_{\mathrm{ST}}$ were plotted against distance separating sampling sites on Pelsaert Island within intervals of $5 \mathrm{~m}$ up to $200 \mathrm{~m}$, intervals of $50 \mathrm{~m}$ up to $1 \mathrm{~km}$, and intervals of $1 \mathrm{~km}$ beyond that, to see at what distance subdivision began to rise.

Another method of estimating neighbourhood size is possible if there is isolation by distance. Slatkin \& Maddison (1990) defined $\hat{M}$ as an estimator of gene flow between two subpopulations: $\hat{M}=N_{\mathrm{e}} m=$ $0.25\left(F_{\mathrm{ST}}{ }^{-1}-1\right)$, where $N_{\mathrm{e}}$ is the effective population size and $m$ is the proportion of migrants in a local subpopulation. For a linear stepping-stone model (a reasonable approximation for $B$. vittatum on Pelsaert Island) without selection, there is a linear decrease of $\log \hat{M}$ with increasing $\log i$, where $i$ is the distance between subpopulations in units of demes. The intercept of that regression gives an estimate of $\log \left(N_{\mathrm{e}} m\right)$ for a single deme. Because $m=1$ in comparisons of a 
deme with itself, the intercept is an estimate of $\log N_{\mathrm{e}}$. Using the length of the neighbourhood derived from the other methods, we estimated $N_{\mathrm{e}}$ from the regression of $\hat{M}$ on distance for the large-scale transect on Pelsaert Island.

Pelsaert Island provided a relatively continuous series of subpopulations over a long distance. To test for the effects of water gaps as barriers to gene flow, we compared regressions of mean $G_{\mathrm{ST}}$ as a function of distance for Pelsaert Island and the Easter group. Comparison of the regressions is complicated by the fact that the estimates of $G_{\mathrm{ST}}$ between pairs of populations at different distances within each set are not independent. To reduce this problem, we grouped the pairwise comparisons into intervals of $1 \mathrm{~km}$, and based the regressions on the mean values. Especially at larger distances, even means can be heavily influenced by a few nonindependent subpopulations. We therefore used only those intervals for which there were at least five individual comparisons.

\section{Results}

\section{Estimates of neighbourhood size}

Of the 1480 snails marked in April 1993, 202 were recaptured the following September. The mean absolute distance moved was $6.4 \mathrm{~m}$, with a maximum of $68 \mathrm{~m}$. Movement was symmetrical about the point of release, with a mean shift of only $0.3 \mathrm{~m}$ (SE 0.9) towards the south. The extent of movement was very similar for small and large snails. Of the 73 resident snails that were recaptured, 61 had diameters $>8 \mathrm{~mm}$ when they were marked, and only 3 had diameters $<5$ $\mathrm{mm}$. In contrast, none of the imported snails was $>8$ $\mathrm{mm}$ when marked, and the mean diameter was $5.2 \mathrm{~mm}$. The movements of the two groups were indistinguishable: the mean $( \pm \mathrm{SE})$ distance moved by the larger, resident snails was $5.9 \pm 0.9 \mathrm{~m}$, compared with $7.0 \pm 1.4 \mathrm{~m}$ by the smaller, imported snails.

The distribution of dispersal distances after 5 months was highly leptokurtic (Fig. 2), with $g_{2}=11.4$. The 38 snails recaptured after 9.5 months, however, showed a much less leptokurtic distribution (Fig. 2), with $g_{2}$ down to 4.8. As expected for a continuing process of diffusion, both the mean and variance of dispersal distances were greater after 9 months. Although only 4 snails were recaptured from each of the groups marked in September 1992 and June 1992, they confirmed the process of continued spread (Table 1). Over the four intervals represented by the recaptures, the regressions of both the log mean $\left(r^{2}=0.989\right)$ and the $\log$ median $\left(r^{2}=0.996\right)$ dispersal distances against time were highly significant $(P<0.01)$. The intercept of the regression for log mean was 0.52 , suggesting that dispersal soon after release may have been slightly greater than later on. Also of importance for the estimation of neighbourhood length is the change from a highly leptokurtic distribution early on to a platykurtic distribution after a year (Table 1). From the regression of kurtosis on time $\left(r^{2}=0.932\right.$,

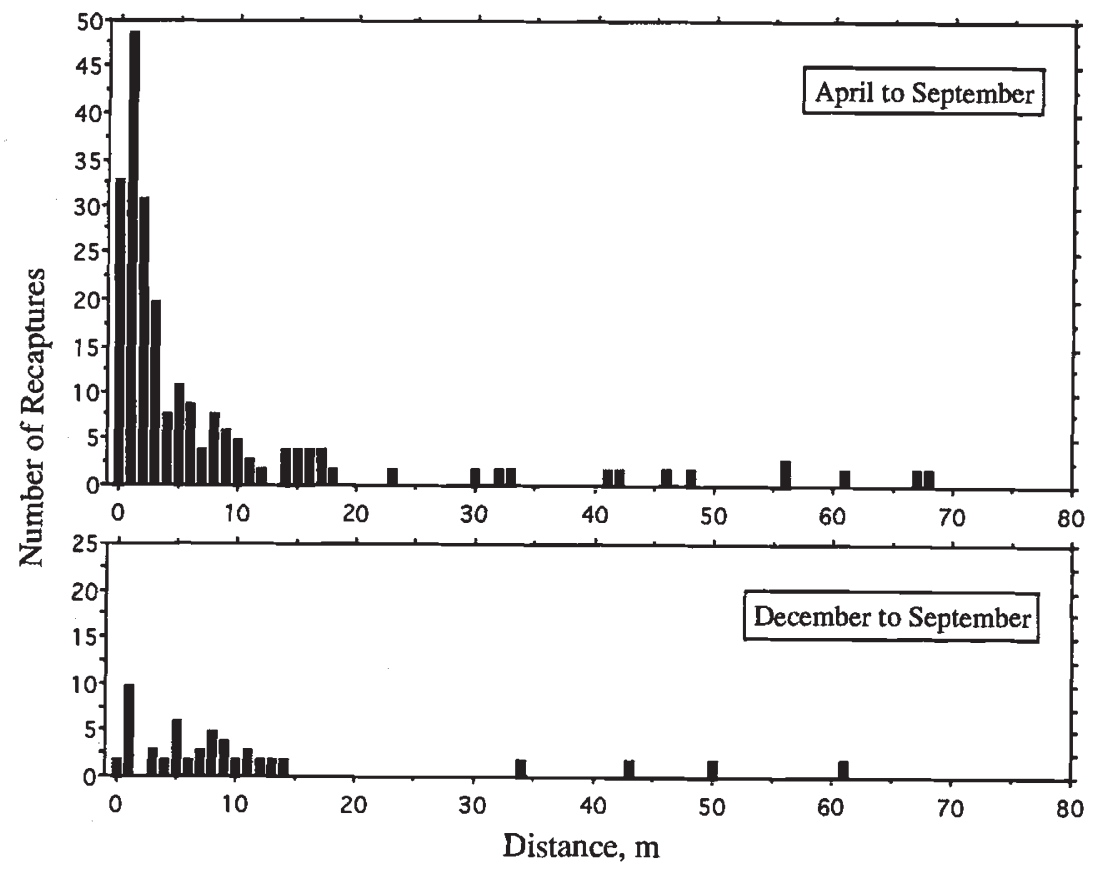

Fig. 2 Frequency distributions of dispersal distances of marked Bembicium vittatum recaptured after 5 months (April to September) and 9.5 months (December to September). 
Fig. 3 Mean $G_{\mathrm{ST}}$ between pairs of samples of Bembicium vittatum at different distances apart on the $300 \mathrm{~m}$ and $1600 \mathrm{~m}$ transects on Pelsaert Island. The dashed line indicates the average value for all comparisons at distances up to $50 \mathrm{~m}$.
Table 1 Summary of distances moved by recaptured Bembicium vittatum at Noddy Shore in September 1993

\begin{tabular}{lrccc}
\hline & \multicolumn{4}{c}{ Date of marking and release } \\
\cline { 2 - 5 } & Apr '93 & Dec '92 & Sep '92 & Jun '92 \\
\hline Interval (months) & 5 & 9.5 & 12 & 15 \\
Sample size & 202 & 38 & 4 & 4 \\
Mean absolute distance $(m)$ & 6.4 & 10.0 & 14.0 & 21.8 \\
Median absolute distance $(\mathrm{m})$ & 2.0 & 6.5 & 11.5 & 21.0 \\
$s^{2}$, directional distance & 181.5 & 242.9 & 47.3 & 480.9 \\
$s$ & 13.5 & 15.6 & 6.9 & 21.9 \\
Kurtosis $\left(g_{2}\right)$ & 11.4 & 4.8 & -0.8 & -1.0 \\
\hline
\end{tabular}

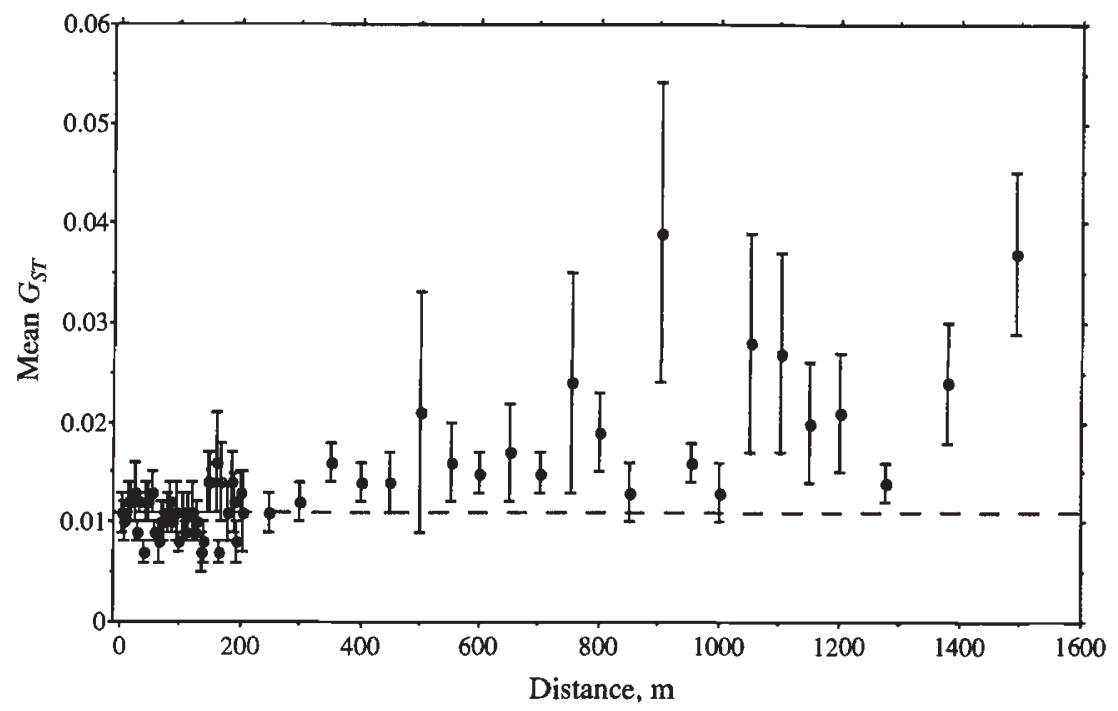

$P<0.05), g_{2}$ after one generation (12 months) was calculated as 1.48 , indicating a slightly leptokurtic distribution.

These patterns confirm that the dispersal in the first 5 months, for which we have the largest number of recaptures, fit with a continuing process. Thus, one estimate of the length of the neighbourhood can be obtained by multiplying the variance in directional dispersal distance over 5 months by 2.4 , which gives $s=20.87 \mathrm{~m}$ at 12 months. Based on $g_{2}=1.48$, we used $3.3 \mathrm{~s}$ as our estimate of the length of the neighbourhood (Wright, 1969), giving a value of about $69 \mathrm{~m}$. The recaptures after 9.5 months, although fewer, represent a larger portion of the generation time, and should be less affected by any disparities in initial dispersal after marking and release. If we base our calculations on $s$ after 9.5 months, the estimated length of the neighbourhood is about $58 \mathrm{~m}$. We take the average $(64 \mathrm{~m})$ as our best estimate from the variance of dispersal distances.
Another estimate is possible from the observed increase in the median dispersal distance with time. From the regression of log median against time, the expected median absolute distance at 12 months is 11 $\mathrm{m}$. Doubling this value accounts for symmetrical dispersal from the point of release, and gives an estimate of $22 \mathrm{~m}$ as the length encompassing half the breeding population. Using Wright's (1969) factor of 2.8 for the length of the neighbourhood gives a value of $62 \mathrm{~m}$, very similar to that calculated from the variance of dispersal distances.

The genetic comparisons provide a third estimate of the length of the neighbourhood. Mean values of $G_{\mathrm{ST}}$ as a function of distance are plotted for the $300 \mathrm{~m}$ and $1600 \mathrm{~m}$ transects in Fig. 3. As a baseline, we determined the mean $G_{\mathrm{ST}}$ for all comparisons at distances up to $50 \mathrm{~m}$, which is clearly within the neighbourhood, and this value $(0.011)$ is also plotted in Fig. 3 . There is considerable variation in the $G_{\mathrm{ST}}$ values, but the means above the 0.011 baseline do not begin to predominate 
Table 2 Estimates of population density, as harmonic means and range ( $\pm 1 \mathrm{SD})$, and neighbourhood size in Bembicium vittatum

\begin{tabular}{|c|c|c|c|c|c|}
\hline \multirow[b]{2}{*}{ Method } & \multirow[b]{2}{*}{ Length $(m)$} & \multicolumn{2}{|c|}{ Noddy Shore } & \multicolumn{2}{|c|}{ Guano Jetty } \\
\hline & & $N$ & Range & $N$ & Range \\
\hline Census (adults $\mathrm{m}^{-1}$ ) & & 111 & $101-124$ & 26 & $16-67$ \\
\hline \multicolumn{6}{|l|}{ Dispersal distances } \\
\hline Variance method & 64 & 7104 & $6464-7936$ & 1664 & $1024-4288$ \\
\hline Median method & 62 & 6882 & $6262-7688$ & 1612 & $992-4154$ \\
\hline \multicolumn{6}{|l|}{ Genetic subdivision } \\
\hline Minimum & 150 & 16650 & $15150-18600$ & 3900 & $2400-10050$ \\
\hline Maximum & 300 & 33300 & $30300-37200$ & 7800 & $4800-20100$ \\
\hline
\end{tabular}

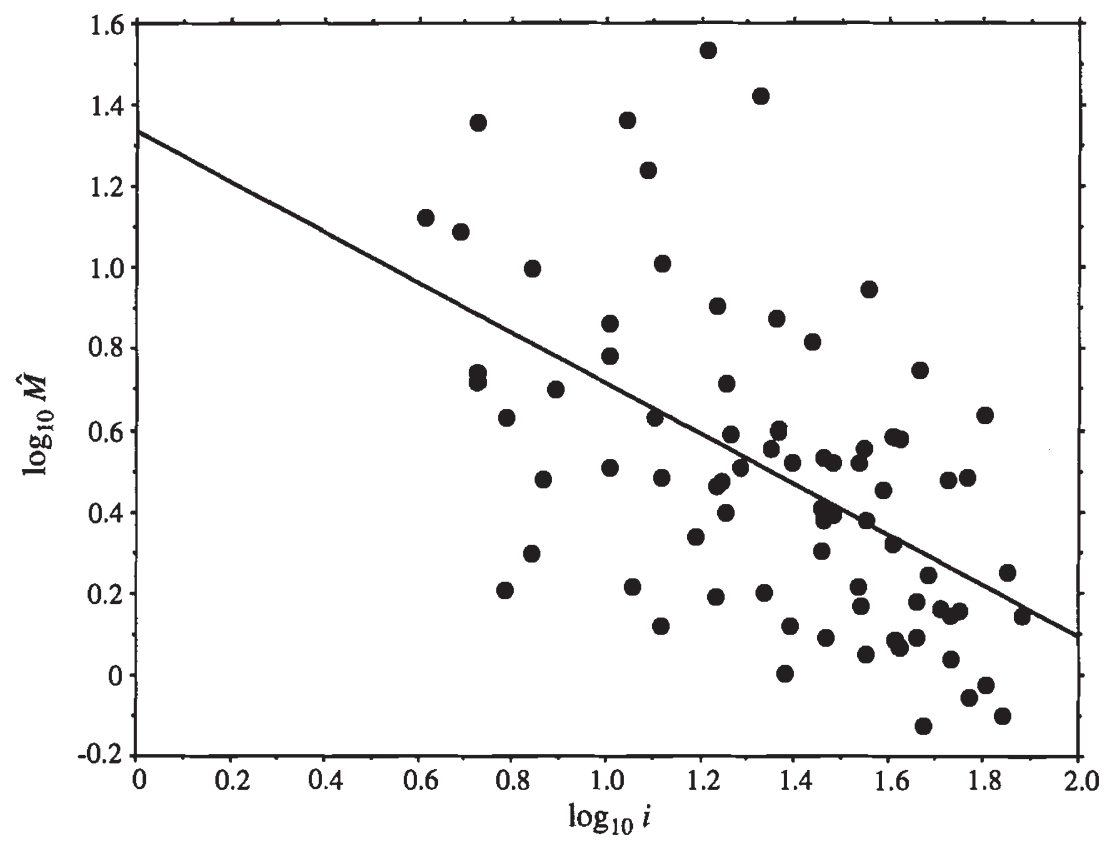

Fig. 4 Regression of $\log \hat{M}$ (estimated level of gene flow) against $\log i$ (distance, in demes) for samples of Bembicium vittatum from the largescale transect on Pelsaert Island. until about $150 \mathrm{~m}$. All mean values for distances $300 \mathrm{~m}$ or greater lie above the line, and the trend is for an increase of mean $G_{\mathrm{ST}}$ at greater distances. Based on this pattern, the estimate of the length of the neighbourhood is 150 to $300 \mathrm{~m}$. Because of the large variance in means over this range, we cannot extract a more precise estimate from the genetic comparisons.

From this set of values for the extent of the neighbourhood and the mean densities at Noddy Shore and Guano Jetty, we estimated neighbourhood sizes (Table 2). The mean density at Guano Jetty was 26 adults per metre along the shore, with a lower bound (mean -1 $\mathrm{SD})$ of 16 . Together with the smallest estimate of neighbourhood length, this gives a lower bound of 992 for the neighbourhood size. At the other extreme, the upper bound of the mean density at Noddy Shore was
124 adults per metre and the extreme upper limit of $300 \mathrm{~m}$ for the length of the neighbourhood gives an upper bound of 37200 in a local breeding population. These are estimates of the total size of the breeding population, not the effective size.

Pairwise estimates of gene flow, $\hat{M}$, between sites on the large-scale transect on Pelsaert Island showed a clear decrease with increasing distance (Fig. 4). The regression was $\log \hat{M}=1.336-0.622 \log i$, with $r^{2}=0.295$. The intercept of 1.336 translates to $N_{\mathrm{e}}=22$, some two orders of magnitude smaller than the estimates of the total size of the adult population. For this regression, we used $150 \mathrm{~m}$ as the length of the deme, which was compatible with the estimates from median dispersal distances and the position of the rise in $G_{\mathrm{ST}}$. If we use $60 \mathrm{~m}$ for the length of the deme, based on the 
mark-recapture study, the intercept increases to 1.575 , and the estimate of $N_{\mathrm{e}}$ increases to 38 , which is still very small.

\section{Isolation by distance}

The plot of $\hat{M}$ against distance (Fig. 4) showed a clear pattern of isolation by distance over the entire $11 \mathrm{~km}$ of Pelsaert island. The patterns of variation in allelic frequencies underlying this relationship are shown in Fig. 5, in which the samples from the large-scale transect and the $1600 \mathrm{~m}$ transect are included. The general picture is one of relatively smooth, spatially coherent variation, but with the changes at different loci occurring at different places along the island. The greatest variation is for $V l p 2$, at which the 76 allele rises clinally from a frequency of about 0.12 to nearly 0.60 over $6 \mathrm{~km}$ in the northern half of the island. The range of frequencies at the Gotl locus was nearly as great, but the change occurred in the southern two-thirds of the island, whereas the $L p p^{89}$ allele rose and fell again over a $6 \mathrm{~km}$ length close to the centre. The only striking exceptions to these relatively smooth gradients were associated with site 110 (km 4.4 in Fig. 5) for the Est4 and Pgml loci. Even low-frequency alleles showed clear spatial patterns. The $P g d^{80}$ allele was not found in the northern third of the island. Even south of the $5 \mathrm{~km}$ position, it reached a maximum frequency of only 0.067 , but it was found in 27 of 31 samples in that section. The $P g m 2^{108}$ allele was similarly restricted, being found at all 28 sites between $5 \mathrm{~km}$ and $10 \mathrm{~km}$, but nowhere exceeding a frequency of 0.075 . These varied patterns show that the large-scale pattern of isolation by distance was not the result of simple clinal variation along the length of the island, but of the effects of displaced smaller-scale variations for the separate loci.

The overall pattern of isolation by distance on Pelsaert Island contrasted with the pattern in the Easter Group (Fig. 6). For comparisons among sites separated
Fig. 5 Allelic frequencies $( \pm S E)$ in samples of Bembicium vittatum from the $1600 \mathrm{~m}$ and large-scale transects on Pelsaert Island, plotted against distance from the northern end of Arthur Island. All alleles with $p \geq 0.05$ in at least two samples are included.

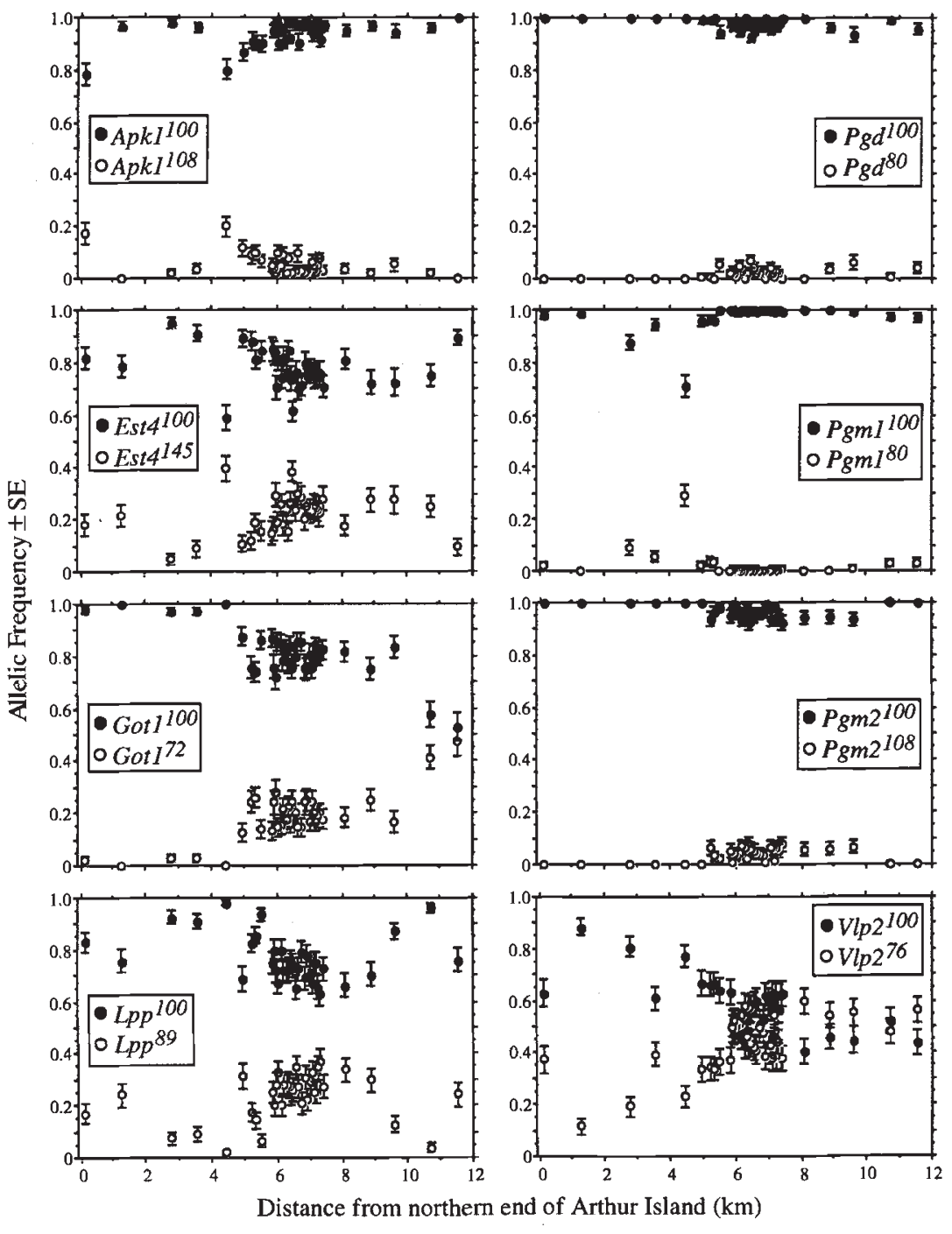



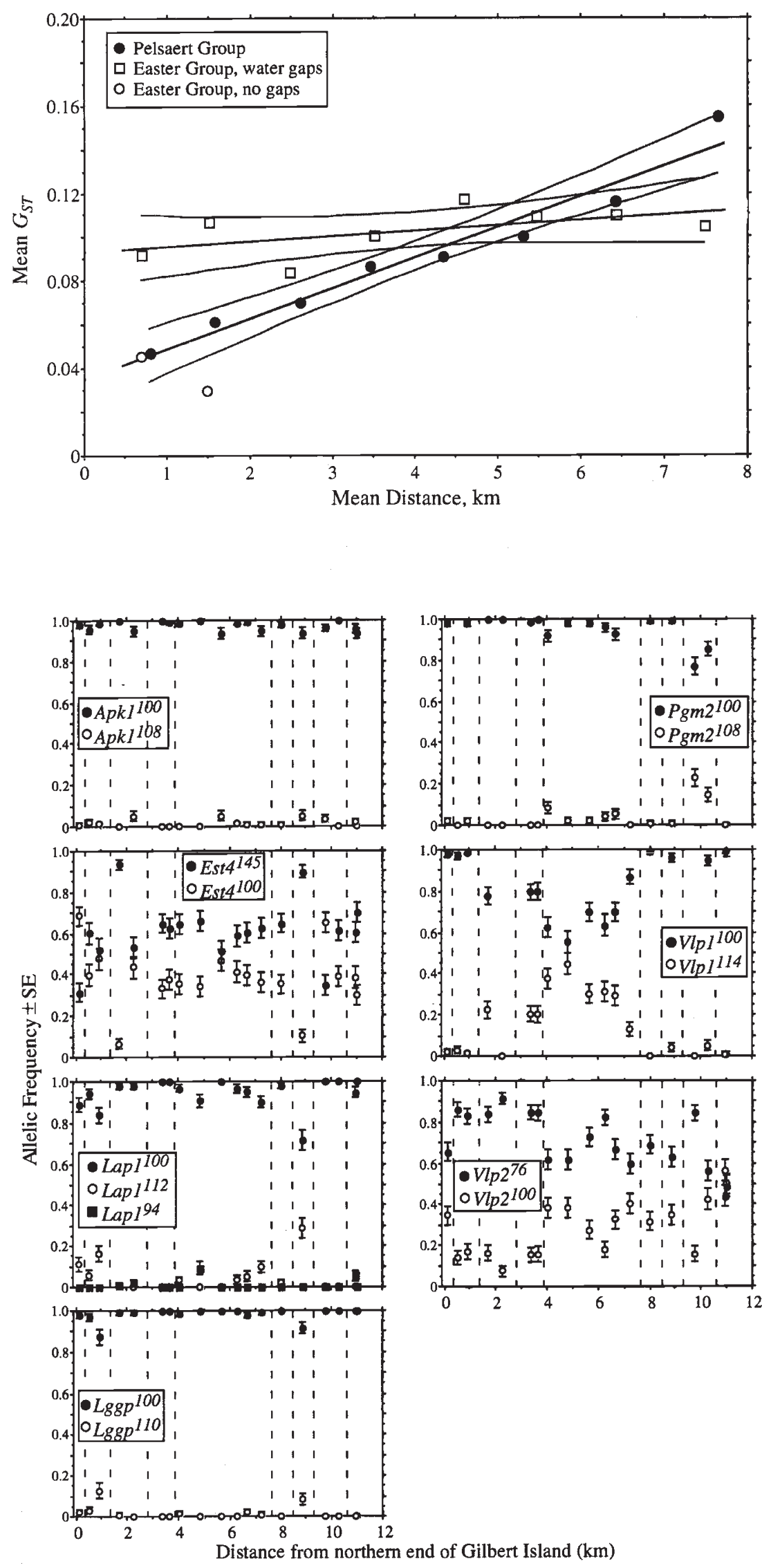

Fig. 6 Regressions (with 95 per cent confidence intervals) of mean pairwise $G_{\mathrm{ST}}$ against geographical distance from the large-scale transect of Bembicium vittatum on Pelsaert Island and from interisland comparisons in the Easter Group, grouping the comparisons by intervals of $1 \mathrm{~km}$. Mean values for within-island comparisons in the Easter Group are shown, but not included in the regressions.

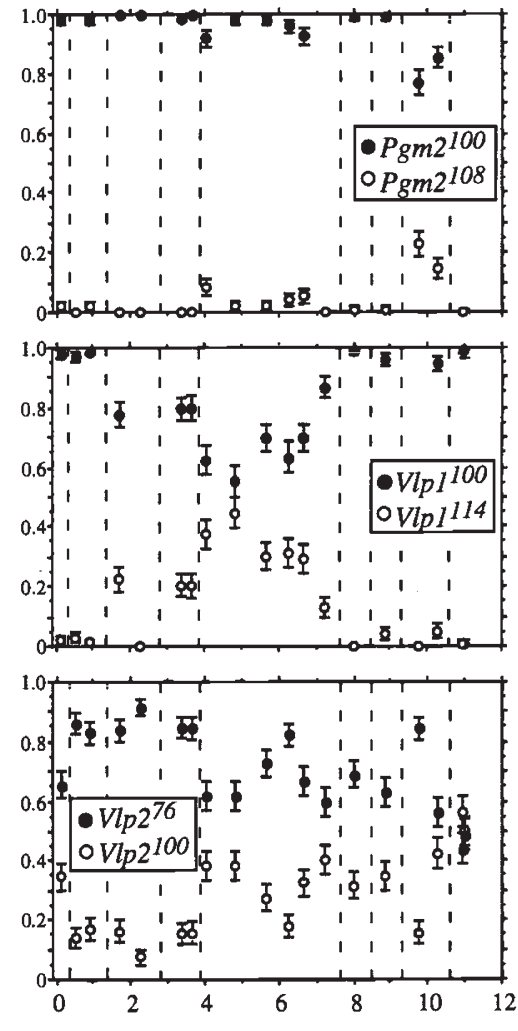

Fig. 7 Allelic frequencies $( \pm S E)$ in samples of Bembicium vittatum from the Easter Group, plotted against distance from the northern end of Gilbert Island. All alleles with $p \geq 0.05$ in at least two samples are included. Dashed lines delineate sites from different islands. 
by water gaps within the Easter series, there was no overall association of genetic subdivision with distance between populations (Fig. 6). That this difference caused by the gaps was confirmed by comparisons between sites from the same islands within the Easter Group. For these, the mean $G_{\mathrm{ST}}$ was no greater than those from Pelsaert Island (Fig. 6). The effect of the water gaps in the Easter Group was a two-fold increase in $G_{\mathrm{ST}}$ for populations separated by $1 \mathrm{~km}$, which is equivalent to the increase that occurred over 4 to $5 \mathrm{~km}$ along the continuous habitat of Pelsaert Island. This effect applied only to these relatively short distances, as $G_{\mathrm{ST}}$ was actually greater for the Pelsaert series than in the Easter Group at distances beyond $7 \mathrm{~km}$ (Fig. 6).

The contrast between the Easter Group and Pelsaert Island was also evident from the patterns of variation at individual loci, which were generally less smooth for the Easter series (Fig. 7). Only Vlp1 showed relatively smooth clinal variation, similar to that seen for several loci on Pelsaert Island. The effect of water gaps was suggested more strongly by Shearwater Island (km 9 in Fig. 7), a small island nearly $1 \mathrm{~km}$ from Keru Island. The sample from Shearwater Island showed striking jumps in allelic frequencies for Est4, Lap1, and Lggp. The distribution of uncommon alleles in the Easter series also did not show the same spatially smooth patterns seen on Pelsaert Island. Instead, the uncommon $A p k 1^{108}, \operatorname{Lap1}^{94}$, and $\operatorname{Lggp^{110}}$ alleles were each found at several sites scattered throughout the Easter series. Thus, there was a clear contrast in the pattern of genetic subdivision among the disjunct populations in the Easter Group compared with that in the relatively continuous series of populations on Pelsaert Island.

\section{Discussion}

It is difficult to obtain precise estimates of neighbourhood size, and the estimates obtained by different methods must be evaluated in terms of possible limitations and biases. Estimates of dispersal rates are prone to three obvious types of bias. The first is that the disturbance caused by the capture, marking and release of the animals can often increase dispersal rates (e.g. Cameron \& Williamson, 1977). This effect was probably small in our study, as disturbance to the habitat was minimal. Although all coral fragments were moved in the censusing of the site, the physical disturbance was no longer evident after only one or two tidal cycles, as the small fragments are moved naturally. The increase in density arising from the importation of marked snails was also minor. At times of heavy recruitment, we have found densities of small $B$. vittatum at the Noddy Shore site nearly as great as our experimental densities. The strongest evidence that the experiment caused little increase in dispersal rates is the strong regression of mean dispersal distance against time, with an intercept of only $3.3 \mathrm{~m}$. This value is an estimate of the initial bias in dispersal rates, and it is small relative to the distance over a full generation.

The second source of bias in mark-recapture estimates of dispersal is that dispersal rates may vary over time. In the case of $B$. vittatum, the strong regressions of both mean and median distances with time indicate that there are no major seasonal variations. The similarity of dispersal distances of small and large snails indicates that changes with development are also small, although we have no information on dispersal rates of recuits less than $2 \mathrm{~mm}$ in diameter. For such small gastropods, even directly developing juveniles can disperse, and some actively initiate drifting and produce mucus threads which slow their sinking rate (Martel \& Chia, 1991a,b). It is also likely that unusually severe storms could sporadically increase dispersal of snails of all sizes.

A third possible bias comes from the difficulty of finding long-distance dispersers (e.g. Coyne et al., 1982). The locally linear distribution of this intertidal species made it possible to sample greater distances than has been done in similar studies of land snails, and the distribution in Fig. 2 gives confidence that few snails moved beyond our study area. Nevertheless, even one snail travelling a great distance can have a large effect on the mean and variance of dispersal. The median dispersal distance, on the other hand, is less sensitive to the rare individual that moves a long way. The similar estimates of neighbourhood length from the variance and median support our view that few snails moved beyond our study area.

Another set of biases can affect the scaling of dispersal distances to generation time. This is especially important for linear distributions, because the estimation of neighbourhood length is strongly affected by the shape of the distribution of dispersal distances (Wright, 1969). Although dispersal distances are typically strongly leptokurtic in the short term, they can become platykurtic over time (Wright, 1969), a change that was evident for $B$. vittatum, and included in our calculation of the length of the neighbourhood. Our estimate of generation time, however, is only approximate. Strictly speaking, the generation time is the mean period between birth of parents and the births of their offspring. Thus, an accurate estimate requires age-specific rates of survivorship and reproduction, whereas we only have estimates of adult survivorship for $B$. vittatum. If older individuals have higher reproductive rates, the generation time will be longer and the neigh- 
bourhood size larger than our estimates. To get some idea of the possible effect, we used the life table in Hughes \& Roberts (1981) for another littorine snail, Littorina rudis. The estimate of generation time based on the age-specific rates is about 25 per cent greater than that based on our simplified approach, suggesting that our estimates may indeed be low. Even if the generation time were actually 16 months, instead of 12 , however, our estimates of the length of the neighbourhood from the mark-recapture study would rise only to $67-80 \mathrm{~m}$, still much smaller than the $150-300 \mathrm{~m}$ indicated by the genetic study.

Although the estimation of neighbourhood length from the spatial scale of genetic subdivision has the obvious disadvantage of being less direct, it has the advantages of being independent of the problematical estimation of generation time and of integrating effects of dispersal over several generations. For example, occasional long-distance dispersal, which is difficult to detect directly, will affect the spatial scale of genetic subdivision. If estimates of neighbourhood size from mark-recapture experiments and genetic comparisons differ, it is likely that the genetic estimates will be larger, as is the case for $B$. vittatum. However, the estimates from our genetic analysis are imprecise. This results partly from sampling errors in the allelic frequencies and from variations among the loci, which could result from either selection or chance. The imprecision could also reflect real variations in dispersal rates on different sections of the shore, despite our attempt to minimize these through our choice of study site. Based on the probable biases, however, it is likely that the length of the neighbourhood is closer to $150 \mathrm{~m}$ than to $60 \mathrm{~m}$.

This distance is large compared with those of land snails. Greenwood (1974) reported standard deviations of dispersal in Cepaea nemoralis of two to 10 per year. He argued that the rates are likely to be much smaller during the first year of life, leaving three years of effective dispersal per generation. On this basis, the diameter of the neighbourhood would be 14 to $69 \mathrm{~m}$. Allozyme comparisons in Helix aspersa indicate a similar scale of about $30 \mathrm{~m}$ (Selander \& Kaufman, 1975). Dispersal is even less in Theba pisana (Cowie, 1984) and Partula taeniata (Murray \& Clarke, 1984), which are more similar in size to $B$. vittatum, with neighbourhood diameters of less than $10 \mathrm{~m}$. It is not clear whether the greater dispersal of $B$. vittatum results from more active crawling by the snails or from passive transport along the shore. That the contrast is not simply between intertidal and terrestrial species is suggested by a comparison with Littorina saxatilis, another littorine snail with direct development. Janson \& Ward (1984) presented allozyme frequencies in 11 samples from a $1 \mathrm{~km}$ transect in Norway, the distances between samples ranging from 4 to $1054 \mathrm{~m}$. We calculated pairwise values of $G_{\mathrm{ST}}$ from these data to test for an effect of distance. For comparisons of samples less than $50 \mathrm{~m}$ apart, the mean $G_{\mathrm{ST}}$ was 0.059 , more than five times as great as for $B$. vittatum at distances as great as $250 \mathrm{~m}$. For samples of $L$. saxatilis separated by more than 500 $\mathrm{m}$, the mean $G_{\mathrm{ST}}$ was 0.078 , similar to that for $B$. vittatum in the discontinuous Easter series of sites, and twice as great as on Pelsaert Island over the same distances. It is not clear from Janson \& Ward (1984) whether $L$. saxatilis was distributed continuously along their transect, but the high degree of subdivision over even very short distances emphasizes that the spatial scale of the neighbourhood found for $B$. vittatum is relatively large for a semiterrestrial snail that disperses primarily by crawling.

For densities of $B$. vittatum that are typical of Pelsaert Island, the implications are that neighbourhoods are relatively large, with our mean estimates ranging from more than 990 to 37000 . Although the genetically effective population sizes are likely to be smaller than these estimates, it seems very unlikely that they are as low as 38 , the estimate from the regression of $\hat{M}$ on distance. The reason for this huge discrepancy is not clear, but it indicates that the actual degree of genetic divergence is greater than expected under Slatkin's (1993) model. This is the first comparison of estimates from Slatkin's (1993) method with more direct estimates, and it highlights the potential difficulties of working from models to estimation. Similar discrepancies have sometimes been found for other methods of estimating gene flow (e.g. Johnson et al., 1988). Presumably the history of colonization and/or natural selection have affected the populations in ways that violate the assumptions of the model, but we have no direct evidence for these. In the absence of a specific explanation, we must accept the estimates from the mark-recapture and positioning of the rise in $G_{\mathrm{ST}}$ as being closer to the actual values. From this, it appears that random drift is unlikely to be important under present circumstances in these populations. Only if there are severe disturbances are these populations likely to become disjointed and small enough for chance to have a significant effect. The relatively smooth gradients of allelic frequencies along the $11 \mathrm{~km}$ of Pelsaert Island support the view that the underlying structure is one of isolation by distance among relatively continuous and large populations.

This continuity emphasizes the importance of barriers to gene flow in favouring genetic subdivision on a finer scale in B. vittatum. This importance is clear from genetic comparisons of populations in landlocked lagoons with those from adjacent open shores (Johnson 
\& Black, 1991). These tidal 'lakes' are separated from the open shores by barriers of coral rubble, and their populations often show large differences in allozyme frequencies from those on the adjacent shores. Throughout the Abrolhos Islands, the genetic subdivision among eight lake populations was nearly twice as great $\left(F_{\mathrm{ST}}=0.277\right)$ as that among their counterparts on adjacent open shores $\left(F_{\mathrm{ST}}=0.152\right)$.

The present study shows that water gaps also are important barriers to gene flow among populations. The comparison between the discontinuous populations in the Easter series and the continuous ones on Pelsaert Island showed a doubling of $G_{\mathrm{ST}}$ associated with water gaps averaging about $1 \mathrm{~km}$ wide. The less continuous patterns of variation in allelic frequencies in the Easter series are further evidence of the importance of the reduced gene flow between islands. This is of special significance for divergence in the Houtman Abrolhos, which include more than 100 islands, most of which support populations of $B$. vittatum. Indeed, although Pelsaert Island shows the potential for genetic continuity over a scale of several kilometres, it is the only place in the Houtman Abrolhos where such potential is realized. There are larger islands in the northern portion of the archipelago, but these have less suitable habitats and only localized populations of $B$. vittatum. Aside from Pelsaert Island, there is no relatively continuous series of populations longer than about $2.5 \mathrm{~km}$, and most are substantially less than this. These distances are smaller than the widths of most clines observed on Pelsaert Island. Thus, the importance of direct development for genetic subdivision is increased in the context of this archipelago of many small islands. The fragmentation of populations increases the likelihood that local peculiarities of history or population structure will affect patterns of genetic divergence. By revealing the spatial scale of gene flow and genetic subdivision in an area with minimal external constraints, the findings on Pelsaert Island emphasize the importance of focussing on the nature of special constraints underlying the patterns of genetic divergence within this species.

\section{Acknowledgements}

We thank Kim Brooks, John Clarke, Karen Parsons, Jane Prince, Michelle Stuckey and Robyn Watts for help in the field, Darcy Hebbert, Caroline Fuery and Michelle Stuckey for electrophoretic analyses, and Prof. Bryan Clarke for comments on the manuscript and for titular suggestions. The Western Australian Department of Fisheries provided accommodation at their field camps in the Houtman Abrolhos Islands. Funds were provided by the Australian Research Council.

(c) The Genetical Society of Great Britain, Heredity, 75, 142-154.

\section{References}

BLACK, R., TURNER, S. AND JOHNSON, M. S. 1994. The early life history of Bembicium vittatum Philippi, 1846. Veliger, 37, 393-399.

BROWN, L. 1991. Genetic variation and population structure in the blacklip abalone, Haliotis rubra. Aust. J. Mar. Freshw. Res., 42, 77-90.

CAMERON, R. A. D. AND WILliamSON, P. 1977. Estimating migration and the effects of disturbance in mark-recapture studies on the snail Cepaea nemoralis. J. Anim. Ecol., 46, 173-179.

CowIE, R. H. 1984. Density, dispersal and neighbourhood size in the land snail Theba pisana. Heredity, 52, 391-401.

COYNE, J. A., BOUSSY, I. A., PROUT, T., BRYANT, S. H., JONES, J. S. AND MOORE, J. A. 1982. Long-distance migration of Drosophila. Am. Nat., 119, 589-595.

EGUIARTE, L. E., BURQUEZ, A., RODRIGUEZ, J., MARTINEZRAMOS, M., SARUKHAN, J. AND PINERO, D. 1993. Direct and indirect estimates of neighbourhood and effective population size in a tropical palm, Astrocaryum mexicanum. Evolution, 47, 75-87.

GREENWOOD, J. J. D. 1974. Effective population numbers in the snail Cepaea nermoralis. Evolution, 9, 513-526.

HUGHES, R. N. AND RoBERTS, D. J. 1981. Comparative demography of Littorina rudis, $L$. nigrolineata and $L$. neritoides on three contrasted shores in North Wales. J. Anim. Ecol., 50, 251-268.

JANSON, K. AND WARD, R. D. 1984. Microgeographic variation in allozyme and shell characters in Littrorina saxatilis Olivi (Prosobranchia: Littorinidae). Biol. J. Linn. Soc., 22, 289-307.

JOHNSON, M. S. AND BLACK, R. 1991. Genetic subdivision of the intertidal snail Bembicium vittatum (Gastropoda: Littorinidae) varies with habitat in the Houtman Abrolhos Islands, Western Australia. Heredity, 67, 205-213.

JoHnSON, M. S., ClARKE, B. AND MURRAY, J. 1988. Discrepancies in the estimation of gene flow in Partula. Genetics, 120, 233-238.

JONES, J. S., LEITH, B. H. AND RAWLINGS, P. 1977. Polymorphism in Cepaea: a problem with too many solutions? Ann. Rev. Ecol. Syst., 8, 109-143.

MARTEL, A. AND CHIA, F.-S. 1991a. Drifting and dispersal of small bivalves and gastropods with direct development. $J$. Exp. Mar. Biol. Ecol., 150, 131-147.

MARTEL, A. AND CHIA, F.-S. 1991b. Foot-raising behaviour and active participation during the initial phase of postmetamorphic drifting in the gastropod Lacuna spp. Mar. Ecol. Prog. Ser., 72, 247-254.

MURRAY, J. AND CLARKE, B. 1984. Movement and gene flow in Partula taeniata. Malacologia, 25, 343-348.

NEI, M. 1973. Analysis of gene diversity in subdivided populations. Proc. Natl. Acad. Sci. U.S.A., 70, 3321-3323.

RICHARDSON, B. J. 1983. Distribution of protein variation in skipjack tuna (Katsuwonus pelamis) from the central and South-western Pacific. Aust. J. Mar. Freshw. Res., 34, 231-251.

RichARDSON, B. J., BAVERTOCK, P. R. AND ADAMS, M. 1986. Allozyme Electrophoresis. Academic Press, New York. 
SCHILTHUIZEN, M. AND LOMBAERTS, M. 1994. Population structure and levels of gene flow in the Mediterranean land snail Albinaria corrugata (Pulmonata: Clausiliidae). Evolution, 48, 577-586.

SELANDER, R. K. AND KAUFMAN, D. w. 1975. Genetic population structure and breeding systems. In: Markert, C. L. (ed.) Isozymes, vol. IV, Genetics and Evolution, pp. 27-48. Academic Press, New York.

SlatKin, M. 1985. Gene flow in natural populations. Ann. Rev. Ecol. Syst., 18, 393-430.
SLATKIN, M. 1993. Isolation by distance in equilibrium and non-equilibrium populations. Evolution, 47, 264-279.

SLATKIN, M. AND MADDISON, w. P. 1990. Detecting isolation by distance using phylogenies of genes. Genetics, 126, 249-260.

wallace, B. 1968. Topics in Population Genetics. W. W. Norton, New York.

WRIGHT, s. 1969. Evolution and Genetics of Populations, vol. 2, The Theory of Gene Frequencies. University of Chicago Press, Chicago. 